Journal of Molecular Structure

Elsevier Publishing Company, Amsterdam. Printed in the Netherlands

\title{
SEMI-EMPIRICAL CALCULATIONS ON THE STRUCTURE OF THE URONIUM ION
}

\author{
S. HARKEMA AND D. FEIL
}

Chemical Physics Laboratory, Twente University of Technology, Enschede (The Netherlands)

(Received 11 April 1972)

\begin{abstract}
Semi-empirical calculations (CNDO/2) on the structure of the uronium ion are presented. Assuming a planar ion with fixed bond lengths, the bond angles involving the heavy atoms can be calculated with fair accuracy. Changes in bond length and angles, which occur upon protonation of the urea molecule, can be explained by the calculations.
\end{abstract}

\section{INTRODUCTION}

The site of protonation in the amide group (carbonyl oxygen or amine nitrogen atom) has been the object of a number of studies. The results obtained by different methods and even by different workers using the same experimental techniques are controversial. The infrared spectra of uronium nitrate have been used to prove $\mathrm{O}$-protonation ${ }^{1,2}$ as well as $\mathrm{N}$-protonation ${ }^{3,4}$. The results of investigations by nuclear magnetic resonance have been reviewed recently by Stewart and Siddall ${ }^{5}$. Theoretical calculations using $a b$ initio electrostatic molecular potentials ${ }^{6}$ favour O-protonation. On the whole, surveying the work in this field, it can be concluded ${ }^{7}$ that there is much more evidence for O-protonation than for $\mathrm{N}$-protonation.

THE URONIUM ION

In the case of uronium nitrate the existence of O-protonated uronium ions, in the solid state, has been established both by neutron ${ }^{8}$ and X-ray diffraction ${ }^{9}$. 


\section{TABLE 1}

BOND LENGTHS $(\AA)$ AND ANGLES $\left({ }^{\circ}\right)$ IN URONIUM NITRATE COMPARED WITH THE CORRESPONDING VALUES IN UREA

\begin{tabular}{llllll}
\hline Bond & $a$ & $b$ & Angle & $a$ & $b$ \\
\hline C-O & $1.311(3)$ & $1.352(2)$ & N (1)-C-N (2) & $122.2(3)$ & $116.6(1)$ \\
C-N (1) & $1.312(3)$ & $1.260(2)$ & N (1)-C-O & $116.3(3)$ & $121.7(1)$ \\
C-N (2) & $1.301(3)$
\end{tabular}

a: Uronium nitrate ${ }^{9}$, bond lengths not corrected for thermal motion.

b: Urea ${ }^{12}$, bond lengths corrected for thermal motion.

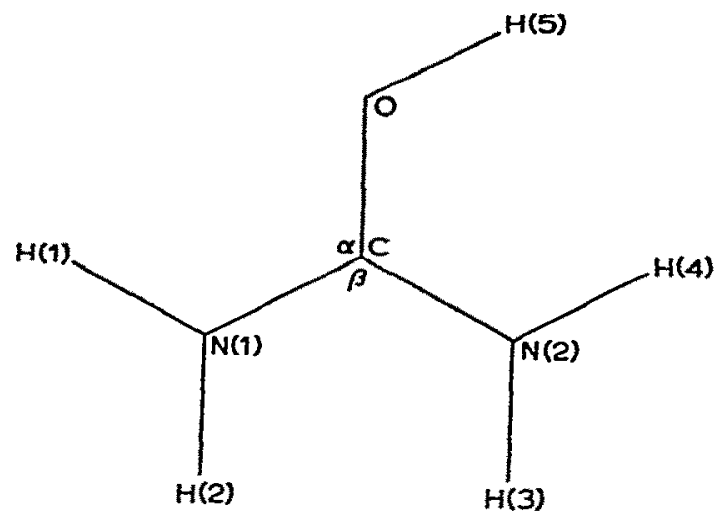

Fig. 1. The geometry of the uronium ion.

O- (or S-) protonated ions have also been found in the crystal structures of $\mathrm{N}$ methyluronium nitrate ${ }^{10}$ and thiouronium nitrate ${ }^{11}$. The diffraction studies on uronium nitrate show that the uronium ion is planar within experimental accuracy. Bond lengths and angles as determined by $\mathrm{X}$-ray diffraction are given in Table 1 together with the corresponding values for the urea molecule ${ }^{12}$. The numbering of the different atoms is given in Fig. 1. From the table it can be seen that the following changes occur when urea is protonated at the oxygen atom:

1. The $\mathrm{C}-\mathrm{O}$ bond becomes longer

2. The $\mathbf{C}-\mathbf{N}$ bond is shortened

3. The two $\mathrm{N}-\mathrm{C}-\mathrm{O}$ angles, which are equivalent in the urea molecule, become significantly different.

The same changes in bond lengths and angles are also found in N-methyluronium nitrate ${ }^{10}$ and thiouronium nitrate ${ }^{11}$.

SEMI-EMPIRICAL CALCULATIONS

In order to see whether semi-empirical calculations might be successful in 
predicting the changes in geometry which occur when urea is protonated, we carried out a number of calculations by the CNDO/2 method ${ }^{13}$. The program used was a slightly modified version of a program written by Segal ${ }^{14}$ and distributed by the Quantum Chemistry Program Exchange.

As the number of parameters which can be varied in the uronium nitrate structure is too large to make a complete minimalization of the energy feasible, we used a model with a number of constraints. In accordance with experimental evidence the uronium ion was assumed to be planar. The $\mathrm{C}-\mathrm{O}$ and $\mathrm{C}-\mathrm{N}$ bond lengths were kept fixed at the experimental values. Bond lengths and angles involving hydrogen atoms were set equal to $1.00 \AA$ and $120^{\circ}$ respectively. By these assumptions the number of parameters which can be varied independently is reduced to two: the angles $\alpha$ and $\beta$ defined in Fig. 1. In the urea molecule, where the two $\mathrm{O}-\mathrm{C}-\mathrm{N}$ angles are equivalent, only one parameter, the angle $\alpha$, remains when the constraints are applied.

\section{BOND ANGLES}

The total energy (sum of electronic energy and core repulsion terms) was calculated for the urea molecule for different values of $\alpha$. The bond lengths in the urea molecule were assumed to be the same as in the uronium ion. Values of the total energy computed are given in Table 2 and Fig. 2. As seen from Fig. 2 the

TABLE 2

TOTAL ENERGY OF THE UREA MOLECULE AS FUNCTION OF $\propto$

\begin{tabular}{llll}
\hline$\alpha$ & $E($ a.u. $)$ & $\alpha$ & $E($ a.u. $)$ \\
\hline 100 & -51.6989 & 125 & -51.7711 \\
105 & -51.7299 & 130 & -51.7534 \\
110 & -51.7561 & 135 & -51.7103 \\
115 & -51.7692 & 140 & -51.6101 \\
120 & -51.7757 & & \\
\hline
\end{tabular}

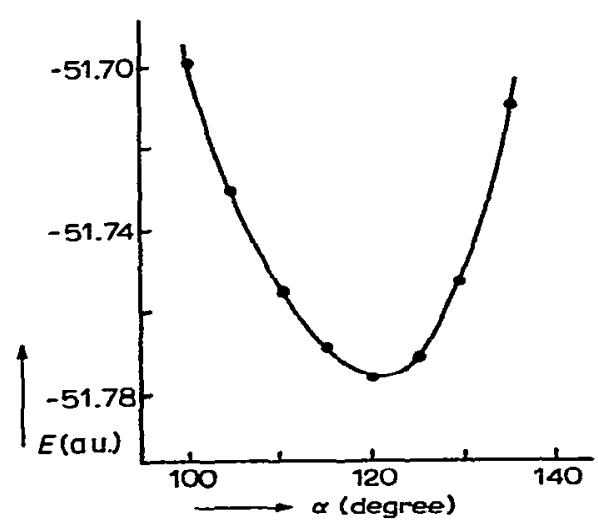

Fig. 2. Total energy of the urea molecule as a function of $\alpha$. 
TABLE 3

TOTAL ENERGY (a.u.) FOR THE URONIUM ION AT DIFFERENT VALUES OF $\alpha$ AND $\beta$

\begin{tabular}{llllcl}
\hline$\beta$ & $\alpha$ & \multicolumn{5}{c}{} \\
\cline { 2 - 6 } & 100 & 110 & 120 & 130 & 140 \\
\hline 100 & -52.2591 & -52.2850 & -52.2990 & -52.3010 & -52.2912 \\
110 & -52.2955 & -52.3177 & -52.3267 & -52.3221 & -52.3037 \\
120 & -52.3175 & -52.3346 & -52.3371 & -52.3240 & -52.2936 \\
130 & -52.3268 & -52.3371 & -52.3310 & -52.3059 & -52.2535 \\
140 & -52.3295 & -52.3278 & -52.3095 & -52.2625 & -52.1546 \\
\hline
\end{tabular}

TABLE 4

TOTAL ENERGY (a.u.) FOR THE URONIUM ION AT DIFFERENT VALUES OF $\propto$ AND $\beta$.

\begin{tabular}{llccc}
\hline$\beta$ & $\alpha$ & & \\
\cline { 2 - 5 } & 110 & 113.3 & 116.6 & 120 \\
\hline 120 & -52.3346 & -52.3372 & -52.3380 & -52.3371 \\
123.3 & -52.3396 & -52.3413 & -52.3412 & -52.3393 \\
126.6 & -52.3384 & -52.3392 & -52.3383 & -52.3354 \\
130 & -52.3371 & -52.3370 & -52.3350 & -52.3310 \\
\hline
\end{tabular}

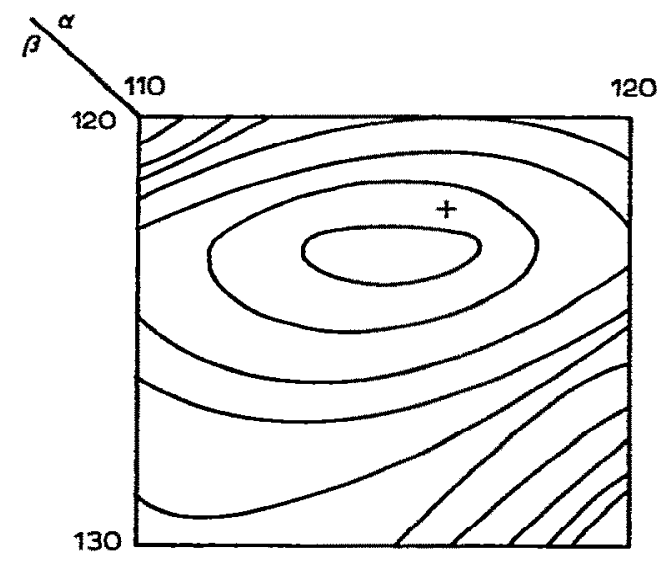

Fig. 3. Contour diagram giving the total energy of the uronium ion as a function of $\alpha$ and $\beta$. The energy difference between two lines is 0.001 a.u. The experimental value of $\alpha$ and $\beta$ is denoted by $+$

total energy has a minimum at about $121^{\circ}$. The experimental value for this angle is $121.7^{\circ}{ }^{12}$. The dipole moment (including atomic dipole moments) calculated was $5.4 \mathrm{D}$. Values of the dipole moment of urea measured in different solvents range from 4.2 to $6.4 \mathrm{D}^{15}$. Subsequently calculations were performed on the uronium ion. The total energy was calculated as a function of the angles $\alpha$ and $\beta$ defined in Fig. 1. Values of the energy computed are given in Tables 3 and 4 and in Fig. 3. 
From Fig. 3 it becomes evident that the calculated energy minimum is not far from the experimental one.

Summarising the results of this section it can be stated that - using the above mentioned constraints on the geometry-the $\mathrm{CNDO} / 2$ method is capable of predicting the changes in bond angles which occur on protonation.

\section{BOND LENGTHS}

When urea is protonated measurable changes in bond lengths take place. The shortening of the $\mathbf{C}-\mathbf{N}$ bond and the lengthening of the $\mathrm{C}-\mathrm{O}$ bond can be readily explained by a Valence Bond (resonance) model as shown by Worsham and Busing ${ }^{8}$. A simple Molecular Orbital model involving $\pi$ electrons only, also gives an explanation for the experimental facts. The urea molecule is a $\pi$ system, containing 6 electrons. The $\pi$ system extends over the $\mathrm{C}, \mathrm{N}$ and $\mathrm{O}$ atoms, accounting for the planarity of the molecule and the lengths of the $\mathrm{C}-\mathrm{N}$ and $\mathrm{C}-\mathrm{O}$ bonds, which are intermediate between a single and a double bond. When urea is protonated at the oxygen atom, the $\pi$ electrons will become more localized at that atom. The resulting effects on the bond orders are: an increase in the $\mathbf{C}-\mathrm{N}$ bond order and a decrease in the $\mathrm{C}-\mathrm{O}$ bond order.

$\pi$ bond orders calculated by means of the CNDO/2 procedure are given in Table 5. The figures given are consistent with the experimental result on bond lengths in the urea molecule and the uronium ion.

\section{TABLE 5}

$\boldsymbol{x}$ BOND ORDERS CALCULATED BY THE CNDO/2 METHOD FOR THE UREA MOLECULE AND THE URONIUM ION

Computations were performed at the point of minimal total energy using the constraints on geometry described in the text.

\begin{tabular}{lll}
\hline Bond & Urea & Uronium ion \\
\hline C-N (1) & 0.478 & 0.597 \\
C-N (2) & 0.478 & 0.593 \\
C-O & 0.687 & 0.443 \\
\hline
\end{tabular}

\section{REFERENCES}

1 M. J. JANSSEN, Spectrochim. Acta, 17 (1961) 475.

2 W. Kutzelnigg and R. Mecke, Spectrochim. Acta, 17 (1961) 530.

3 V. M. Davies AND L. Hopkins, Trans. Faraday Sac., 53 (1957) 1563.

4 E. SPINner, Spectrochim. Acta, 15 (1959) 95.

5 W. E. Stewart and T. H. Siddale, Chem. Rev., 70 (1970) 517.

6 R. Bonaccorsi, A. Pullman, E. Scrocco and J. Tomasi, Chem. Phys. Lett., 12 (1972) 622. 
7 R. B. Homer AND C. D. Johnson, in J. ZaBicky (editor), Chemistry of Amides, Wiley-Interscience, New York, 1970, Chap. 3.

8 J. W. Worsham and W. R. Busing, Acta Crystallogr., B25 (1969) 572.

9 S. HaRkema AND D. Feil, Acta Crystallogr., B25 (1969) 589.

10 W. F. Selman and S. Harkema, Progr. Rep., Chem. Phys. Lab., Twente Univ. of Technology, (1971) C36.

11 D. Feil ANd 'V. Song Loong, Acta Crystallogr., B24 (1968) 1334.

12 A. W. Pryor and P. L. SANger, Acta Crystallogr. A26 (1970) 543.

13 J. A. Pople and G. A. Segal, J. Chem. Phys., 44 (1966) 3289.

14 G. A. Segal, Program No. 91, Quantum Chemistry Program Exchange, Bloomington.

15 A. C. McClellan, Tables of Experimental Dipole Moments, Freeman, San Francisco, Calif., 1963, p. 45. 